\title{
Post-Injection Sciatic Nerve Palsy in a Patient with PIVD
}

\author{
Himanshu Bhayana ${ }^{1 *}$ and Anil K Jain ${ }^{2}$ \\ ${ }^{1}$ Department of Orthopaedics, GTB Hospital \&UCMS, India \\ ${ }^{2}$ Director Professor \& Head, Department of Orthopedics, GTB Hospital \&UCMS, India
}

Submission: September 07, 2018; Published: September 24, 2018

*Corresponding author: Himanshu Bhayana, Senior resident, Department of Orthopaedics, Guru Teg Bahadur Hospital, Delhi, 110095, India, Tel: +919599149380; Email: Himanshu.bhayana.mamc@gmail.com

\begin{abstract}
Prolapsed intervertebral disc (PIVD) commonly presents as lower back ache associated with features of radiculopathy. We present an unusual case of a patient presenting with foot drop and our diagnostic and therapeutic protocol for the same. Our patient was a 40-year-old female who was diagnosed as a case of PIVD L4-L5 and was advised for non-operative treatment. During her treatment, the patient received intramuscular analgesic therapy immediately following which the patient reported a foot drop in the left lower limb. While the patient was initially thought to present with an acute neurological worsening of the affected disk requiring urgent decompression. However, post injection nerve palsy was kept as one of the differentials. The diagnosis of post injection palsy was confirmed by obtaining an NCV study and MRI neurography. She was subsequently managed conservatively via a foot drop splint, oral analgesic therapy and neurotropic agents. On follow up at 6 months she had complete neurological recovery. Post injection palsy can mimic as further prolapse of disc in a case of PIVD. It is imperative to differentiate these two as the management follows different course, the differentiation can be done using MR neurography.
\end{abstract}

Keywords: MR Neurography; Foot drop; PIVD; Post injection palsy

\section{Introduction}

Prolapsed intervertebral disc is one of the common health problems leading to work disability [1]. Many cases of prolapsed intervertebral disc present with back pain and radiculopathy. In patients with prolapsed intervertebral disc at the L4- L5 level, the positive predictive value of sensory deficit is $50 \%$, while motor deficit is present in $54 \%$ of the cases [2]. We present a rare case of prolapsed intervertebral disease where the patient presented with foot drop following an intra-muscular injection and the uncommon diagnostic modalities which we used to establish the cause of foot drop.

\section{Case Report}

A 40-year-old female had low back ache for last 3 months. The pain was sharp in character, which increased on standing and movement and decreased on rest. The pain was radiating to right lower limb. She also complained of numbness in right L5 dermatome region. The pain gradually progressed to an intensity of $7 / 10$ and interfered with activity of her daily living. She initially presented to a private practitioner who sought baseline investigations including MRI (Figure 1) and the diagnosis of prolapsed intervertebral disc (L4-L5) was established. Patient was advised for elective discectomy. Initial treatment in the form of oral and intramuscular analgesics was prescribed.

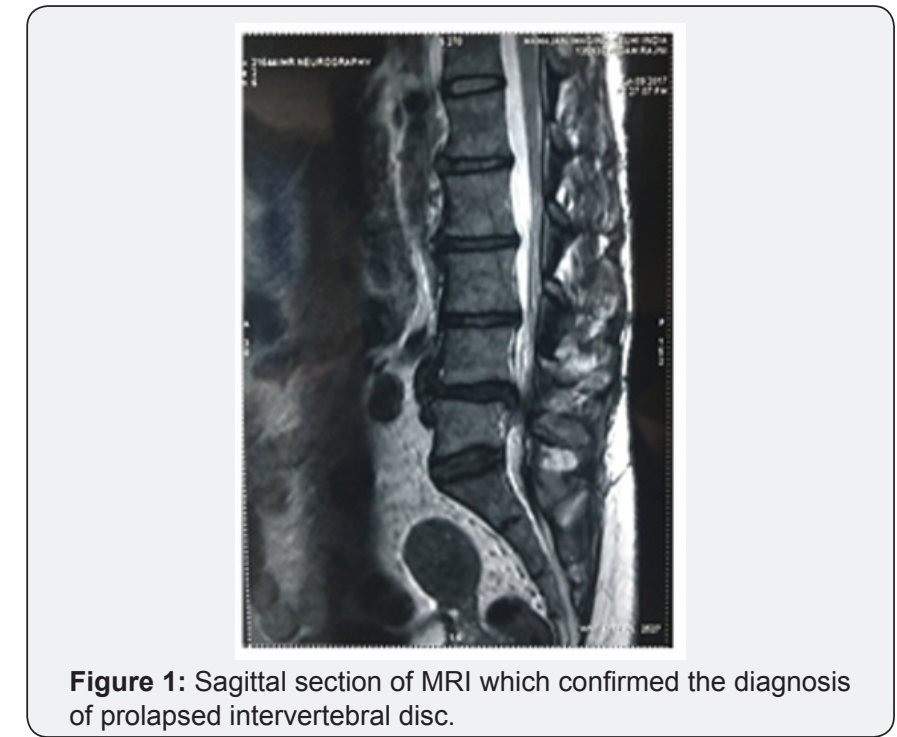

Although the patient had immediate relief from the back ache following intramuscular injection of analgesic, she reported foot drop in left lower limb within minutes of the injection. The treating surgeon at this time suspected rapid progression of neurological deficit secondary to disc prolapse and the patient 
was suggested to undergo emergent disc removal. It was at this stage that she presented to our institute, for a second opinion. The patient was able to walk for long distance without appearance of pain. On examination, there was no para spinal spasm or list. The straight leg raising test was asymptomatic bilaterally. The motor power of left tibialis anterior, peroneus longus, peroneus brevis, extensor hallucis longus and extensor digitorum longus were $0 / 5$ as per MRC grading. The motor power in other group of muscles of left lower limb was normal $(5 / 5)$. There was no sensory deficit in the left lower limb.

Although rapid worsening of neurology in the patient could suggest further prolapse of the involved disc, it was the sudden relief in pain which provoked us to seek answers beyond prolapsed disc. Another possibility which could explain the symptoms was post injection nerve injury. The management of neurological worsening due to further prolapse of disc is emergent decompression while post injection palsy can be managed over conservative lines. In view of these two radically different treatment methodologies for each of the individual diagnoses, we obtained nerve conduction velocity studies with the aim to establish a diagnosis. The NCV revealed motor axonal involvement of left common peroneal nerve.

The MR neurography of hip joint revealed soft tissue around sciatic nerve (due to fibrosis) (Figure 2). The diagnosis of post injection palsy of peroneal component of sciatic nerve was thus established.
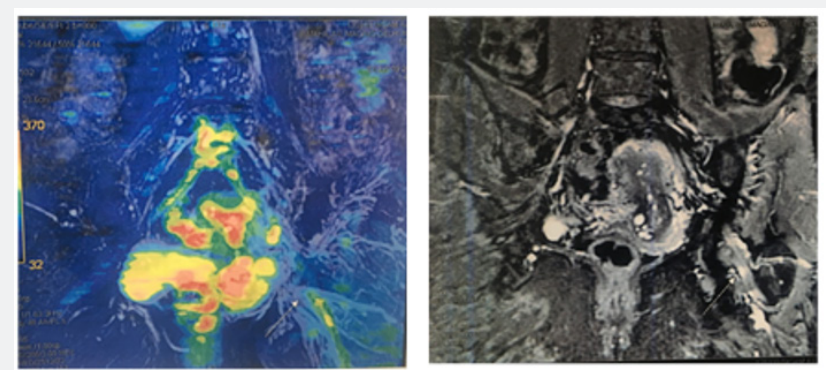

Figure 2: MR neurography demonstrating fibrosis in left sciatic nerve.

Patient was further managed conservatively on foot drop splint, oral analgesics and neurotrophic agents. Clinical examination one month later revealed improved power at tibialis anterior, EHL and EDL. However, motor power in peroneus longus and peroneus brevis was still 0/5. Patient was kept under regular follow up for appreciation of further neurological recovery. At 6 months of follow up, clinical examination revealed complete neurological recovery with power of 5/5 in all muscles of the anterior and lateral compartment. Informed consent was taken from the patient for publishing this case.

\section{Discussion}

Radiculopathy from lumbar disc herniation can be a result of mechanical compression, ischemia or inflammatory irritation of the nerve root. Oral and intramuscular analgesics are widely used for initial management of slipped disc. However it was indeed unfortunate that management of one pathology led to the development of another pathology.

The World Health Organization reported that around 12 billion injections are administered every year and 50\% of them are unsafely administered [3]. Sciatic nerve is the most common nerve to be affected following intramuscular injection $[4,5]$. Around $90 \%$ of patients with sciatic nerve injury have immediate onset of symptoms [6,7]. Motor function is more severely affected compared from sensory component [8]. Peroneal division is more frequently involved, and foot drop is most common presentation due to weakness in dorsiflexion and eversion [4,9-10].

Although there is a huge burden of post injection palsy, the condition is frequently underdiagnosed due lack of clinical suspicion. Clinical examination supplemented with nerve conduction velocity study is useful in diagnosis of sciatic nerve injection injury [11]; however, they cannot define the precise location of the site of nerve lesion. Magnetic resonance neurography (MRN) is a new technique which allows detection of peripheral nerve injury and can reveal neural injury even on fascicular micro-structural level [12]. Kline et al. [4] reported spontaneous recovery in $68 \%$ patients who had common peroneal division injury following post injection sciatic nerve injury [4]. Kakati et al. [13] also reported favorable outcome in patients with post injection palsy with partial deficits, however external and internal neurolysis may be needed if spontaneous recovery is not observed with non-operative management.

The article also reinforces the art and importance of history taking and the importance of building differentials before initiation of treatment. It was only after careful history taking we could suspect the cause of foot drop in a patient of prolapsed intervertebral disc to be post injection sciatic nerve involvement. Prolapsed disc is treated by discectomy and decompression while post injection palsy is best managed by non-surgical modalities. If post injection palsy was not suspected, the patient would have been at the receiving end of surgical intervention which was not needed for her.

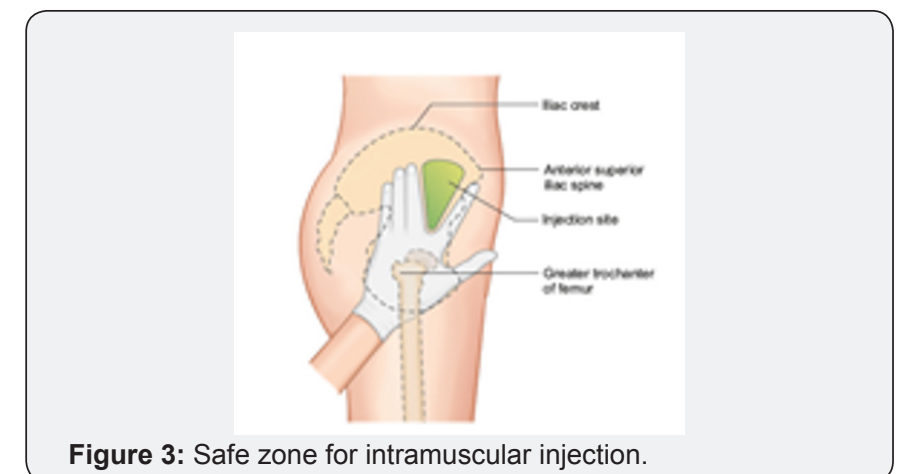

The article also reinforces the importance of knowing safe corridors for gluteal injection. Understanding of the anatomic course of sciatic nerve and proper training is a must to avoid such instances in future. In gluteal region, the ventrogluteal area (gluteal triangle as depicted in Figure 3) is safer with only one reported complication [14]. The subcutaneous fat is less at this site, with high bulk of gluteus muscle. 
Even after extensive search in the literature, we could not find similar report of post injection palsy in a patient of prolapsed intervertebral disc leading to neural deficits. Also, there is no literature emphasizing importance of MR neurography in such a condition.

\section{References}

1. Bina MS, Ghahvechi AM, Afshin H, Behnaz S, Kamyar G (2013) Effect of body mass index on inpatient rehabilitation outcomes after singlelevel discectomy. Neurosurg Qtly 25(2): 260-263.

2. Jensen OH (1987) The level-diagnosis of a lower lumbar disc herniation: the value of sensibility and motor testing. Clin Rheumatol 6(4): 564-569.

3. Miller MA, Pisani E (1999) The cost of unsafe injections. Bull World Health Organ 77(10): 808-811.

4. Kline DG, Kim D, Midha R, Harsh C, Tiel R (1998) Management and results of sciatic nerve injuries: a 24-year experience. J Neurosurg 89(1): 13-23.

5. Tak SR, Dar GN, Halwai MA, Mir MR (2008) Post injection nerve injuries in Kashmir: a menace overlooked. J Res Med Sci 13(5): 244247.

6. Kim DH, Murovic JA, Tiel R, Kline DG (2004) Management and outcomes in 353 surgically treated sciatic nerve lesions. J Neurosurg 101(1): 8-17.
7. Yeremeyeva E, Kline DG, Kim DH (2009) Iatrogenic sciatic nerve injuries at buttock and thigh levels: the Louisiana State University experience review. Neurosurgery 65(4 Suppl): A63-A66.

8. Gilles FH, French JH (1961) Postinjection sciatic nerve palsies in infants and children. J Pediatr 58: 195-204.

9. Mishra P, Stringer MD (2010) Sciatic nerve injury from intramuscular injection: a persistent and global problem. Int J Clin Pract 64(11): 1573-1579.

10. Villarejo FJ, Pascual AM (1993) Injection injury of the sciatic nerve (370 cases). Childs Nerv Syst 9(4): 229-232.

11. Pandian JD, Bose S, Daniel V, Singh Y, Abraham AP (2006) Nerve injuries following intramuscular injections: a clinical and neurophysiological study from North west India. J Peripher Nerv Syst 11(2): 165-171.

12. Stoll G, Bendszus M, Perez J, Pham M (2009) Magnetic resonance imaging of the peripheral nervous system. J Neurol 256(7): 10431051.

13. Kakati A, Bhat D, Devi BI, Shukla D (2013) Injection nerve palsy. J Neurosci Rural Pract 4(1): 13-18.

14. Muller-Vahl H (1985) Isolated complete paralysis of the tensor fasciae latae muscle. Eur Neurol 24(5): 289-291.

\begin{tabular}{l} 
Your next submission with Juniper Publishers \\
will reach you the below assets \\
- Quality Editorial service \\
- Swift Peer Review \\
- Reprints availability \\
- E-prints Service \\
- Manuscript Podcast for convenient understanding \\
- Global attainment for your research \\
- Manuscript accessibility in different formats \\
( Pdf, E-pub, Full Text, Audio) \\
- Unceasing customer service \\
Track the below URL for one-step submission \\
https://juniperpublishers.com/online-submission.php \\
\hline
\end{tabular}

